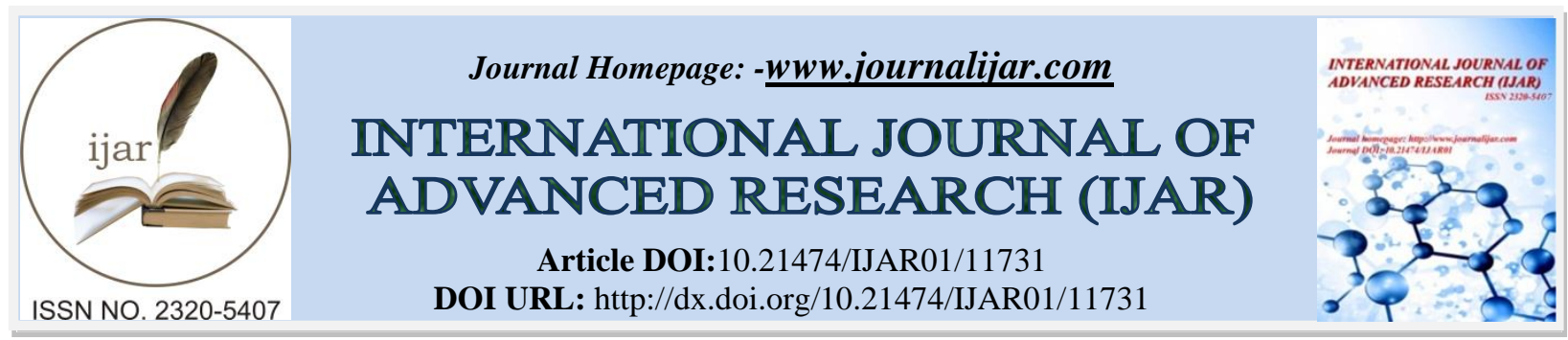

RESEARCH ARTICLE

\title{
DUTIES AND RESPONSIBILITIES OF CLINICAL BIOCHEMIST IN PSYCHIATRY HOSPITAL
}

\section{Phukan J.K ${ }^{1}$, Bora G.K $\mathbf{K}^{2}$ and Yadav $\mathrm{S}^{3}$}

1. Assistant Professor, Department of Biochemistry, LGB Regional Institute of Mental Health, Tezpur, Assam.

2. Reaearch Officer, Biochemistry (corresponding author) RARI for GID, Borsojai, Bhetapara, Guwahati-28, Assam.

3. Demonstrator, Department of Biochemistry FAAMCH, Barpeta, Assam.

\section{Manuscript Info}

Manuscript History

Received: 15 July 2020

Final Accepted: 18 August 2020

Published: September 2020

Key words:-

Laboratory Medicine, Medical

Biochemist, Quality Assurance, Clinical

Psychology, Psychiatric Social Worker

\section{Abstract}

The duties and responsibilities of Clinical Biochemists are evolving. Some of the classical duties and responsibilities of Clinical Biochemists in a Tertiary Psychiatry hospital are basically in the area of research, education and service. Some general rules of success for younger Clinical Biochemist in his/her field are also important topic of discussion. We are living in very competitive times and Clinical Biochemists must learn to adapt very quickly to the continuing changes in our discipline. We are yet to realize the best times of this exciting profession.

Copy Right, IJAR, 2020,. All rights reserved.

\section{Introduction:-}

Laboratory Medicine has contributed for centuries to the diagnosis of human disease. Despite this, the duties and responsibilities of laboratory scientists and physicians are still evolving. It may thus not be a mere repetition, my attempt to review briefly this subject in the 21 st century. Obviously, most of the material that I will discuss is very well known to practicing laboratorians. ${ }^{1}$

One of my ambitions is to use to this forum to explain to newcomers what it is that we do and, most importantly, provide them with some advice that may help them to enjoy successful careers. My background is mostly in Clinical Biochemistry and this presentation will be based towards this discipline. However, I believe that the outlined principles will likely be applicable to other laboratory subspecialties as well. I should also caution the reader that this is a personal perspective and not a review of the literature. In fact, I do not cite much literature and I assume full responsibility for the ideas presented herein. Furthermore, I would like to stress that when using the term clinical or medical biochemist I do not make any distinction between these two types of specialists. ${ }^{2}$

\section{What is a clinical Biochemist?}

To put it by way of exclusion, I should say that a laboratory scientist is not exactly a researcher or a teacher or a manager or a clinical consultant, or an administrator or a physician but, at the same time, it is all of the above. Moreover, Clinical Biochemists can be separated into various categories by degree (MD vs. PhD), by duty (education, service or research) or by employer type (academic vs. Non-academic hospital, private laboratory, industry, government, etc.). These analyses suggest that our profession is extremely diverse, and it may be difficult to find any laboratory scientists with exactly the same duties. In the late 1980s and early 1990s, the notion was put forward by some of us that the duties and responsibilities of laboratorians, and especially of Clinical Chemists, can be successfully fulfilled by technologists and technical managers. ${ }^{3}$ 
The overzealous desire of hospital administrators to save money prompted them to adopt this principle. The consequences were job losses and lack of interest of young scientists to enter the field. This notion, underlined with the motto "Clinical Biochemists are useless, overpaid Super techs" has damaged severely the reputation of our profession, many professionals as well as the hospitals that adopted it. It is now very clear that this experiment was a failure and that the notion was erroneous. However, what are the duties and responsibilities of clinical Biochemist? These evolve around three major themes: Service, Education and Research. ${ }^{4}$

\section{Service}

It should be remembered that the unique identity of a "Clinical Biochemist' is defined by the service component of the profession responsibilities in service are very diverse. Clearly, laboratory technologists are not qualified or trained to perform clinical consultation, sophisticated quality assurance and control, detailed instrument evaluation, complex method development and evaluation, validation and trouble-shooting or are capable of introducing specialized programs. One can cite numerous examples of valuable, professional expertise that can be used by clinical laboratories to set-up new programs. One classical contemporary example is the introduction of "Maternal Serum Screening"' programs for prenatal diagnosis of Down syndrome and neural tube defects. A few years ago, this screening was performed on second trimester maternal serum, analyzed for alpha-fetoprotein, human choriogonandotropin and estriol. Nowadays, there is compelling evidence that first trimester screening may improve the detection rate and, at the same time, cut down on the rate of false positives. Others postulate that it may be necessary to run first and second trimester programs for best performance. The issue of screening for first or second trimester is complex because there is an array of new biomarkers, including inhibin and pregnancy-associated plasma protein A (PAPP-A) as well as modern ultrasonography. The decisions as to which tests should be done, with or without ultrasonography, are quite delicate. Furthermore, the generated data need to be interpreted with specific algorithms that will calculate the risk and then provide suggestions for appropriate clinical action (amniocentesis, abortion, etc.). Such algorithms have been developed by various researchers and companies (at least seven are commercially available now), and the results obtained are not identical. Also, designing a requisition that will capture all the clinical, demographic and other information in an ethical manner is not easy. The implementation of such a program in a teaching hospital must take into account that research should be promoted with such samples, to discover new biomarkers for the future. Clearly, such a program will require the collaboration of the clinical biochemist, the ultrasonographer, the geneticist and the genetic counsellor. Clinical Biochemist has major roles to play in the laboratory and participate decisively as a medical team player in delivery of high quality patient care. ${ }^{5}$

Table 1:- Some service responsibilities of clinical Biochemist ${ }^{6}$

1. Clinical consultation

2. Laboratory management

3. Quality assurance and quality control

4. Accreditation-manuals-documentation

5. Cost containment

6. Instrumentation selection and evaluation

7. Method evaluation/validation/trouble-shooting

8. Implement special programs (see example below)

9. Survey of customer needs/satisfaction

10. Information technology

11. Staff selection and evaluation

\section{Education}

In academic hospitals, clinical Biochemist to carry out the bulk of the teaching at the postgraduate and professional program levels like MSc Nursing, clinical Psychology M.Phil, Psychiatry Social Worker MPhil, MD Psychiatry and last not the least the Phd Scholars of different departments like Psychiatry Nursing, Clinical Psychology and Psychiatry Social Worker. Furthermore, academic laboratory scientists should participate in the organization and coordination of new courses. Nowadays, there are numerous opportunities for creating web-based and only limited by our imagination electronic-based media for teaching. Clinical Biochemists are also frequently called upon to organize workshops, symposia and conferences at the national and international level. Moreover, continuing education is now becoming an important part of maintaining certification and competence in many professions, including Laboratory Sciences. ${ }^{7}$ 
Table 2:- Some educational responsibilities of Clinical Biochemist ${ }^{[8]}$

Teach at levels:

1. Undergraduate

2. Graduate

3. Professional programs (Diploma)

4. Technologists

5. Medical students

6. Physicians

7. Organize and coordinate new courses

8. Web-based teaching

9. Organize workshops, symposia, conferences

10. Continuing education

\section{Research}

The research activities of clinical Biochemist are method development and evaluation, laboratory support to clinical research in which the laboratory scientist will be a co-investigator, as well as individually funded research which involves grants, graduate students, Post-Doctoral Fellows and projects related to mechanisms of disease, translational, as well as basic research.

Table 3:- Some research activities of Clinical Biochemist ${ }^{8}$

1. Method development and evaluation

2. Lab support to clinical research (co-investigator)

3. Individually funded

4. Graduate students

5. Post-Doctors

6. Mechanisms of disease

7. Translational research

8. Basic research

\section{What are the needs of hospitals for clinical Biochemist?}

This has always been debated by hospital administrators. My recommendation to non-academic Psychiatry hospitalsis to hire a full-time Clinical Biochemist forevery 500 hospital beds and one Clinical Biochemist per 100150 beds in academic hospitals. Clinical Biochemist will split their time between service, education and research. At academic Psychiatry institutions, where clinical consultation is important, my recommendation is to mix-up the staff so that medically oriented and science-oriented professionals are working together.

\section{Rules of success}

Success of an individual is attributed of the individual hard work, dedication, enthusiasm, etc. This will be important during interactions with physicians and other investigators. Clinical Biochemists must be attend at least two scientific conferences a year, preferably one that is of a general nature and one that is more specialized to the interest of the individual.

Table 4:- Some rules of success ${ }^{8}$

Over and above the usual:

1. hard work

2. dedication

3. enthusiasm, etc.

\section{Upgrade your knowledge continuously:}

1. 2 conferences/year (1 general, 1 specific)

2. Read journals such as Nature, Science

3. Medline, web searches

4. Stay abreast of current "fashions" of science and technology

\section{Develop a specific expertise which is recognized:}

\section{Regionally}


2. Nationally

3. Internationally

Table 5:- The "Nobody" rules 8

1. Nobody will give you research space unless you prove that you "deserve" it.

2. Nobody will give you protected time for research. You have to create it yourself.

3. Nobody will likely ask you to design and co-ordinate a course. You must recognize the need yourself and then jump-in and do it.

4. Nobody will ask you to write a grant but if you get one, your boss will be very proud.

5. Nobody will ask you to be "distinguished" but if you can be, your hospital will love it.

Another way of keeping an eye into research developmentsin science in general is to subscribe and read one or more of the top multidisciplinary scientific journals. It is not so important to read the actual manuscripts of these publications but to scan the journal for new technologies as well as read the commentaries and other news that are presented on a weekly basis. Nowadays, one can search with keywords thousands of publications through "Index Journals" to keep up with what is going on in a specific area of research. Another important goal of academic clinical Biochemist would be the development of a specific expertise which is recognized regionally, nationally and internationally. ${ }^{8}$

\section{Conclusions:-}

The duties and responsibilities of laboratory scientists are well known and they have been published repeatedly in job descriptions and professional journals. In my opinion, the issue is not what the duties and responsibilities are, but rather, how these can be fulfilled in a manner that helps the patient, the hospital. We should not accept the notion that research in our discipline should be restricted to incremental technological advances and evaluations, or to a supportive role. On the other hand, if we were to be effective teachers, we must continually upgrade our knowledge, identify the new trends in technology and science and be prepared to accept the changes. Since our profession and its areas of activity are evolving continuously due to technological advances, we should adopt a very flexible approach towards change. It is important for those who work at academic institutions to realize that this is a competitive environment which requires their involvement in academicwork at all levels. Those who work at academic institutions must do academic work. Another important is to maintain throughout their careers high moral and ethical standards. Our profession requires extensive interactions with industry and our reputation and credibility can only be maintained if we are fair and our decisions are objective and free of biases and financial conflicts. Clinical Biochemists will ensure that the future of laboratory science and medicine is bright in Psychiatry hospital as well as all modern hospitals.

\section{References:-}

1. Gornall AG. Future education and training requirements of clinical biochemists.ClinBiochem 1976;9:56 - 61 .

2. Authors anonymous. The future of clinical chemistry and its role in healthcare: a report of the Athena Society. ClinChem 1996;42:96 - 101.

3. Colliera CP, Crowe AT, Stinson RA, Chu SY, Houlden RL. The continuing professional development of the Canadian Society of Clinical Chemists and the Canadian Academy of Clinical Biochemists.ClinBiochem 2001;34:91- 6 .

4. Burritt MF. The profession in an uncertain environment.ClinChem 1996;42:6.

5. Pearson MJ. The clinical role of clinical biochemists. Ann ClinBiochem 1999;36:691 - 9.

6. Eleftherios PD. Duties and responsibilities of laboratory scientists. ClinicaChimicaActa 319 (2002) $111-115$

7. Hooper J, O'Connor J, Cheesmar R, Price CP. Tutorial software for clinical chemistry incorporating interactive multimedia clinical cases. ClinChem 1995;41:1345 - 8.

8. Eleftherios PD. Duties and responsibilities of laboratory scientists. ClinicaChimicaActa 319 (2002) $111-115$. 